* Sayonara Grillo Coutinho Leonardo da Silva. Mestre e Doutora em Ciências Jurídicas PUC Rio, Professora Adjunta Departamento de Direito Social e Econômico Programa de Pos-Graduação em Direito Universidade Federal do Rio de Janeiro. sayonara@direito.ufrj.br

** Eleonora Kira Valdez de Moura: Pesquisadora no Grupo de Pesquisa Configurações Institucionais e Relações de Trabalho - CIRT. Mestre em Direito - UFRJ. Bacharel em Estatística UERJ e em Ciências Jurídicas e Sociais UFRJ. lelekira@gmail.com

\section{O que os atores demandam perante o supremo tribunal federal em matéria trabalhista?}

\author{
WHAT DO THE ACTORS DEMAND BEFORE \\ BRAZILIAN SUPREME COURT CONCERNING LABOR \\ MATTERS?
}
Sayonara Grillo Coutinho Leonardo da Silva* Eleonora Kira Valdez de Moura**

Resumo: Este artigo busca compreender as normas e regras que os atores sociais, políticos e empresariais contestam no Supremo Tribunal Federal envolvendo políticas trabalhistas, por meio do estudo das ações diretas de inconstitucionalidade propostas em momentos de intensa judicialização, em uma perspectiva que privilegia as demandas, catalogadas pelo conteúdo das petições iniciais, como forma de apreender as múltiplas leituras possíveis aos direitos laborais no campo da interpretação constitucional. A pesquisa aponta um novo fenômeno: a participação de outros atores, além dos tradicionais representantes da relação capital versus trabalho, descortinando uma seara de reflexões sobre a contribuição da sociedade na elaboração dos conteúdos normativos constitucionais.

Palavras-chave: Judicialização, Trabalho, Supremo Tribunal Federal, Interpretação constitucional.

\begin{abstract}
The article intends to understand what do the actors demand before Brazilian Supreme Court in labor matters, by studying direct actions of unconstitutionality sued at moments of intense judicialisation, under the perspective which not only privileges the decisions, but also the arguments brought in the petitions, as a way to aprehend the multiple readings of labor rights in the field of constitutional interpretation. This research points to a new phenomenon: the involvement of actors other than traditional representatives of capital versus labor relationship, which reveals a field for several studies about the contribution of society in the creation of constitutional normative content.
\end{abstract}

Keywords: judicial review, labor matters, Brazilian Supreme Court. 


\section{INTRODUÇÃO}

O exercício do controle concentrado de constitucionalidade pelo Supremo Tribunal Federal (STF) é tema relevante no cenário jurídico brasileiro e tem sido objeto de um conjunto de expressivos estudos acadêmicos, embalados por tradições teóricas distintas e múltiplas vertentes explicativas. Todavia, são escassas as investigações sobre o funcionamento e o papel do STF em matéria laboral, em especial a judicialização dos conflitos trabalhistas no âmbito de nossa corte suprema. Embora pululem análises acerca da judicialização da política e das relações sociais no Brasil contemporâneo, há lacuna na literatura voltada para a compreensão do papel dos atores coletivos e sindicais na contestação ao direito posto e das respostas dadas pelas instituições judiciárias às demandas concernentes à Constituição e que envolvam a configuração de institutos jurídicos e princípios reitores do direito laboral.

O presente artigo é fruto das pesquisas realizadas pelo grupo de pesquisa Configurações Institucionais e Relações de Trabalho (CIRT), que se dedica a acompanhar as decisões proferidas pelas cortes superiores, bem como os conflitos e práticas dos atores empresariais, sindicais e de partidos políticos, referentes às instituições trabalhistas, no âmbito do Programa de Pós-Graduação em Direito da Universidade Federal do Rio de Janeiro. Busca contribuir para superar a escassez de produções acadêmicas a respeito das ações propostas perante o Supremo Tribunal Federal, envolvendo os atores sindicais e trabalhistas. A partir do recorte temporal 1988-2012, almeja-se ainda evidenciar os períodos em que foram propostas, proporcionalmente, mais ações diretas de inconstitucionalidade (ADIs) em matéria de labor, sistematizar tais ações, apresentá-las e refletir sobre as possibilidades para a análise da atuação dos atores na conformação das instituições do trabalho.

\section{OBSERVAÇÕES METODOLÓGICAS}

Destacar o papel da interpretação e das instituições para a configuração dos direitos é hoje senso comum que não precisa ser repassado. Em sociedades de constitucionalização recente, a concretização da Constituição passa necessariamente pela superação de sua apreensão como mero documento político e admissão de sua normatividade. Em sociedades pluralistas, a 
interpretação das normas constitucionais é realizada por uma sociedade aberta de intérpretes, ou seja, trata-se de uma atividade na qual estão envolvidas todas as potências públicas e os que vivem a norma e têm papel ativo no processo hermenêutico (HÄBERLE, 1997, p. 40). Neste sentido, se são relevantes os estudos sobre as decisões judiciais, não é menos importante olhar para "os agentes conformadores da realidade constitucional” (HÄBERLE, 1997, p. 12), pois "é impensável uma interpretação da Constituição sem o cidadão ativo e sem as potências públicas” (HÄBERLE, 1997, p. 13-14).

Com base nesta perspectiva, este estudo pretende compreender o que os atores demandam perante o Supremo Tribunal Federal em matéria trabalhista, por meio do estudo das ações diretas de inconstitucionalidade propostas em momentos de intensa judicialização. Relembre-se que enquanto na ordem constitucional precedente somente o Procurador-Geral da República poderia propor ação direta perante o Supremo, na Constituição de 1988 o rol de legitimados para propor ação direta de inconstitucionalidade foi ampliado e contempla o Presidente da República, a Mesa do Senado Federal, a Mesa da Câmara dos Deputados, a Mesa de Assembleia Legislativa ou da Câmara Legislativa do Distrito Federal, o Governador de Estado ou do Distrito Federal, o Procurador-Geral da República, o Conselho Federal da Ordem dos Advogados do Brasil, os partidos políticos com representação no Congresso Nacional e as confederações sindicais ou entidades de classe de âmbito nacional.

No âmbito do direito constitucional, a pesquisa parte do pressuposto exposto por Häberle de que a interpretação não é um evento exclusivamente estatal, pois a ele diversas forças políticas têm acesso, é atividade, que potencialmente diz respeito a todos (1997, p. 23). A catalogação dos atores políticos, econômicos e sindicais que postulam a declaração de inconstitucionalidade de normas que versam sobre direito e processo do trabalho é relevante para permitir indagar sobre a extensão dos intérpretes da Constituição do Trabalho, reconhecidos ou não como legitimados ativos pelo Supremo Tribunal Federal.

Em sociedades democráticas, os Tribunais são arenas, espaços para os quais convergem postulações de diferenciados atores políticos e intérpretes do direito para a afirmação de seus interesses e de suas concepções de Estado e de sociedade. A variação do uso dos tribunais por esses sujeitos demonstra que distintos modos de judicialização podem emergir de contextos institucionais semelhantes (TAYLOR; DA ROS, 2008, p. 829). 
Variegados usos da judicialização são observados quando se estudam as demandas propostas nas cortes pelos atores políticos e econômicos. Em instigante trabalho, no qual examinam resultados contingentes da judicialização, Matthew M. Taylor e Luciano Da Ros observam como, em 20 anos de redemocratização, as oposições políticas utilizaram de modo diverso o recurso às ações judiciais (2008, p. 838-843). Como tática de oposição, tem-se uma judicialização na qual a demanda é proposta com o objetivo de explicitar um obstáculo a uma regra para desqualificar políticas públicas do governo, para denunciar, vetar ou retardar práticas governamentais consideradas equivocadas pelos demandantes. A busca por uma arbitragem de interesses em conflito foi observada quando os atores contestam regras que envolvem atribuições e redistribuição de poderes e responsabilidades a partidos, entes políticos, federativos, instâncias judiciais etc. Os atores esperam diminuir impactos negativos na conformação dos recursos de poder atribuídos às instituições de diversas naturezas e reduzir prejuízos políticos e econômicos.

Porém, não apenas as oposições atuam para submeter ao Judiciário matérias em torno das quais figuram como minorias parlamentares, prolongando a disputa legislativa. Há casos em que "se busca a 'mão amiga' da instituição máxima do Poder Judiciário, para que implemente ou se pronuncie de forma favorável a políticas públicas de interesse do próprio governo." (TAYLOR; DA ROS, 2008, p. 842). É o que ocorre quando a judicialização é utilizada como instrumento de governo, com a qual o governo ou partido governamental manifesta sua oposição a medidas congressuais, contrárias a seus interesses e/ ou impopulares. O Poder Judiciário é requerido para superar impasses legislativos, paralisias decisórias, "corrigir erros" de administrações anteriores, afastar leis aprovadas sem a chancela política do governo, retirar do ordenamento estatutos legais desfavoráveis ao Executivo etc. (TAYLOR; DA ROS, 2008, p. 843).

Por conseguinte, a catalogação das ações propostas perante o Supremo Tribunal Federal em matéria laboral se justifica não somente para estudar a interpretação da Constituição por um raio mais amplo de intérpretes, como também para examinar como a judicialização é utilizada no mundo do trabalho.

Na coleta de dados para a pesquisa, optamos por utilizar, como universo amostral, o conjunto de petições iniciais disponibilizadas no endereço eletrônico do STF, que foram lidas e selecionadas a partir de parâmetros predefinidos. Todas as petições iniciais das ações diretas de inconstitucionalidade (doravante apenas ADI ou ADIs, no plural), das ações declaratórias de constitucionalidade 
(ADC ou ADCs) e das arguições de descumprimento de preceito fundamental (ADPF ou ADPFs) foram lidas e as informações extraídas sistematizadas em quadro-resumo.

O quadro-resumo contém seis variáveis, a saber: a) "Data" (dia em que a petição foi distribuída ao Ministro Relator); b) "Situação da ADI”, para indicar o andamento processual que constava no endereço eletrônico do STF no momento da pesquisa; c) "Dispositivo legal impugnado"; d) "Causa de pedir", que apresenta os dispositivos constitucionais apontados pelo postulante como tendo sido violados pela regra impugnada; e) Nome do "Ministro Relator' e, por fim, a variável f) "Legitimado Ativo", que relaciona o ator que inicia a ação (ainda que não esteja enumerado no rol previsto no artigo 103 da CRFB).

A tabulação dos dados e a elaboração dos gráficos viabilizaram uma análise quantitativa preliminar das variáveis, tanto de forma isolada quanto em correlação umas com as outras. O Painel das Ações realizado até o momento não contém as entidades que ingressam no curso da ação e requerem admissão como amicus curiae e não indica as ações diretas de inconstitucionalidade por omissão.

De acordo com as estatísticas disponíveis no portal eletrônico do STF, atualizadas até 31 de dezembro de 2012, 4.820 ADIs foram ajuizadas desde 1988. Considerando-se o número informado pelo STF e procedendo-se a uma seleção segundo os critérios cumulativos de causa de pedir (regra constitucional apontada como violada - artigos $7^{\circ}, 8^{\circ}, 9^{\circ}, 10^{\circ}, 11^{\circ}$ ou $114^{\circ} \mathrm{CFRB}$ e artigo $10^{\circ}$ do ADCT) ou dispositivo legal impugnado (lei, portaria ou resolução contestada), é possível afirmar que, embora representem apenas $4 \%$ (quatro por cento) do total de ações propostas no Supremo Tribunal Federal, fornecem um panorama significativo dos debates legislativos e jurisprudenciais coetâneos com as atividades de redesenho do direito material do trabalho, do direito processual do trabalho e do direito constitucional do trabalho, na medida em que existem ADIs nas quais tanto a causa de pedir, quanto o dispositivo constitucional impugnado compunham o bloco de constitucionalidade, como é o caso das ações que impugnam regras atinentes à reforma do Poder Judiciário.

Dentre as ações disponíveis no controle concentrado de constitucionalidade estudadas, a preponderância das ADIs é inequívoca. A comparação entre as distribuições de frequência de ações revela que entre 1988 e 2012 as ADIs em matéria trabalhista totalizaram 199 feitos, enquanto as ADCs e as ADPFs somaram respectivamente 5 e 33, que representamos no seguinte gráfico: 


\section{GRÁFICO 1}

Distribuições de frequências das ações relativas ao controle concentrado de constitucionalidade em matéria trabalhista entre 1988 e 2012

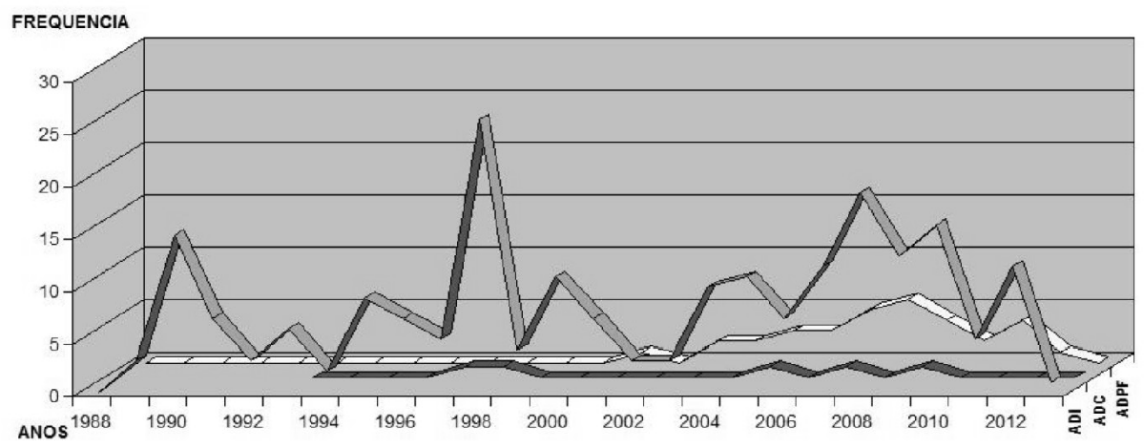

Fonte: Banco de Dados - CIRT/PPGD/UFRJ

Diante da relevância quantitativa das ADIs no panorama do controle concentrado de constitucionalidade, o presente estudo se volta a apresentar prioritariamente tais ações. O índice de 4\% (quatro por cento) pode sugerir que o tema não é representativo no universo geral das Ações. Não significa, porém, que o Supremo Tribunal Federal não seja uma arena judiciária relevante para os atores do mundo do trabalho. Afinal, existem outros tipos de writs (como os mandados de injunção, por exemplo) com mecanismos de acesso à corte constitucional pela via difusa (Recurso Extraordinário), que demonstram um paulatino crescimento da procura pelo STF em matéria de direito individual ou coletivo (sindical) do trabalho. As Súmulas Vinculantes e as Repercussões Gerais em matéria trabalhista versam sobre temas significativos e as ADCs têm sido utilizadas prioritariamente como estratégia de governo, para eximir as administrações públicas - federal, estaduais e municipais - das decisões pacificadas que lhe são desfavoráveis no âmbito da Justiça do Trabalho.

De toda sorte, o recurso às ADIs demonstra o grau de litigiosidade no cenário público nacional quanto a regras, leis, resoluções e portarias, sejam as que concretizam a Constituição de 1988, sejam as que reformulam o direito e as instituições jurídicas laborais. Por outro lado, a atividade legislativa, a atuação das instituições governamentais e o protagonismo do Executivo Federal se somam às controvérsias entre forças políticas, econômicas e sociais no período pósconstituinte que impulsionam as demandas por atuação do Supremo Tribunal 
Federal e justificam a investigação deste fenômeno, não obstante o baixo número de acórdãos examinando o mérito das ações.

Em síntese, o panorama das ADIs propostas perante o STF, que envolvem regras atinentes ao mundo laboral, permite, do ponto de vista dos atores, (a) verificar a pluralidade dos intérpretes da Constituição do Trabalho; (b) refletir sobre os usos da judicialização pelos atores políticos, governamentais e sindicais; e (c) apontar os momentos cruciais do pós-constituinte nos quais o trabalho adquiriu relevância na litigância perante o STF e, com isto, observar os contextos da judicialização.

\section{INTENSIFICAÇÃO DA JUDICIALIZAÇÃO: PERÍODOS CULMINANTES DE PROPOSITURA DE AÇÕES DIRETAS DE INCONSTITUCIONALIDADE}

As demandas para a declaração de inconstitucionalidade de leis sobre matéria trabalhista não seguiram padrão uniforme desde a promulgação da Constituição de 1988. As questões trabalhistas permaneceram em debate no Supremo Tribunal Federal pelos 24 anos de vigência da Constituição, com média de aproximadamente oito ações propostas por ano. Ao logo do intervalo pesquisado, houve expressivo aumento na propositura das ações em períodos determinados. Como demonstramos anteriormente (SILVA; MOURA, 2014), é possível visualizar períodos de maior ou menor contestação judicial às reformas e políticas trabalhistas implementadas ao longo do intervalo estudado. Todavia, não há correspondência necessária entre os momentos de intensa judicialização e de amplo debate público sobre o direito do trabalho, sendo razoável perquirir se maior judicialização coincide ou não com contextos políticos de reformas trabalhistas expressivas.

Em quatro dos 24 anos examinados, a propositura das ADIs teve incidência significativamente relevante, para o que consideramos os anos cuja frequência na propositura atingiu ou ultrapassou o valor da média aritmética simples em mais de 50\%, ou seja, igual ou maior que doze ações.

Segundo tal critério, as demandas propostas foram muito relevantes nos anos de 1990, 1998, 2007 e 2008 com 15, 26, 12 e 19 ações propostas, respectivamente. Índice de judicialização trabalhista no STF - consistente em percentual resultante da divisão entre o número de ações sobre questões laborais e o total de ADIs ajuizadas a cada ano (SILVA; MOURA, 2014) - confirma que, nos períodos de 1990, 1998 e 2007, a procura pelo Supremo Tribunal Federal 
foi expressiva e envolveu mais da metade das ADIs propostas no Tribunal naqueles anos. A correlação entre incidência significativa do ajuizamento com o contexto político do período e o protagonismo presidencial foi examinada em estudo anterior (SILVA; IGREJA; MOURA, 2009).

\section{GRÁFICO 2}

Comparação entre as frequências anuais e a média $(=7,96)$ das ações diretas de inconstitucionalidade em matéria trabalhista entre 1988 e 2012

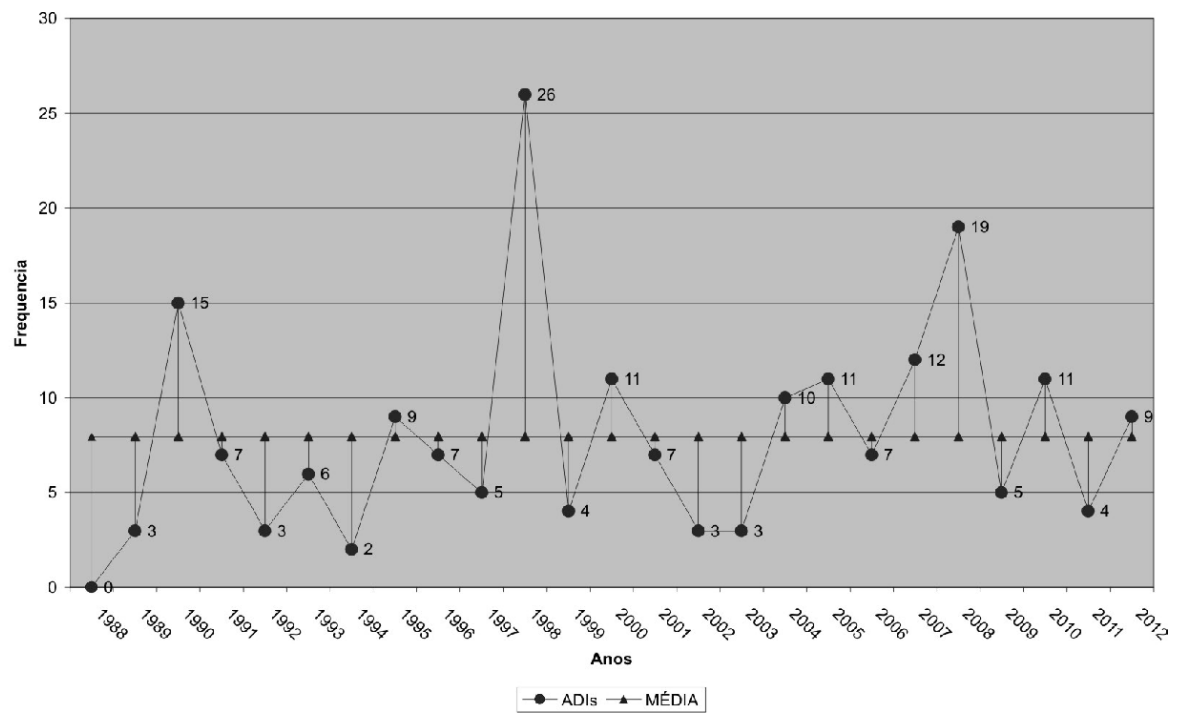

Fonte: Banco de Dados - CIRT/PPGD/UFRJ apud SILVA; MOURA(2014).

\subsection{ARELEVÂNCIADA POLÍTICATRABALHISTANA OPOSIÇÃO AO EXECUTIVO FEDERAL}

No ano de 1990, foram propostas 15 ações diretas. A análise realizada demonstra como a contestação à política econômica de contenção de salários e preços e à abertura comercial indiscriminada da economia brasileira foi a tônica das ações propostas no ano em que Collor de Mello assumiu a Presidência da República. Nas 15 ADIs de 1990, foram arguidas 29 inconstitucionalidades, sendo as mais frequentes a violação ao princípio do direito adquirido (CRFB, art. $5^{\circ}, \mathrm{XXXVI)}$ e o desrespeito ao princípio da irredutibilidade salarial (CRFB, art. $\left.7^{\circ}, \mathrm{VI}\right)$. Em todas elas, foram atacados atos normativos oriundos do Poder Executivo. Sete ADIs foram apresentadas por entidades sindicais representativas 
dos trabalhadores, cinco por partidos políticos e apenas uma pelas representações patronais, o que demonstra a confluência de interesses entre o empresariado e o governo de Fernando Collor de Melo naquele momento.

A afirmação dos conceitos de liberdade e autonomia sindical e de proibição da interferência e da intervenção do Estado na estrutura sindical também estiveram presentes, com a impugnação feita pela Central Única dos Trabalhadores (CUT) e o Sindicato Nacional dos Taxistas (SNT) ao então recém instituído arquivo de entidades sindicais. As ações foram extintas por ilegitimidade ativa, com o STF estreitando a interpretação sobre o rol de legitimados para o ajuizamento de Ação Direta de Inconstitucionalidade. As Centrais Sindicais, entidades construídas de modo autônomo, paralelamente ao sistema sindical tradicional e oficialmente estabelecido pela Consolidação das Leis do Trabalho, não foram reconhecidas como entidades de classe de âmbito nacional para fins de acesso à jurisdição constitucional.

A contestação à política salarial esteve presente nas ações propostas pela CUT, pela Confederação Geral dos Trabalhadores (CGT) contra o Fator de Reposição Salarial e pela Confederação Nacional dos Trabalhadores Metalúrgicos (CNTM) que utilizaram as ADIs como instrumento de oposição, para se contrapor ao Plano Collor e sua supressão dos índices de antecipação salarial, que provocaram perda de $84,32 \%$ nos salários, somente em março daquele ano.

As ações propostas pela Confederação Nacional de Trabalhadores na Saúde (CNTS) e a Confederação das Associações Comerciais do Brasil (CACB) sobre suspensão de decisões de dissídios coletivos, embora possam ser classificadas como ações que versam sobre arbitragem de interesses em conflito (envolvendo instâncias judiciárias do TST e TRTs), relacionam-se com a política de contenção salarial. Do mesmo modo, a ação proposta pela Central Única dos Trabalhadores do Distrito Federal (CUT-DF) e a Confederação Nacional dos Trabalhadores em Educação (CNTE) sobre negociação coletiva, que envolve os espaços de ação e negociação dos sujeitos coletivos.

A Confederação Nacional dos Trabalhadores na Agricultura (CONTAG) e CNTM também foram protagonistas na contestação às políticas governamentais implementadas por Collor de Melo no que concerne à participação nos lucros e resultados e à negociação coletiva, em verdadeira utilização da judicialização como tática de oposição, conforme a classificação de Taylor e Da Ros. 
A Confederação dos Servidores Públicos do Brasil (CSPB), a CGT e a CNTS procuraram assegurar o espaço de atuação e a legitimidade para demandar em juízo nas ADIs que versaram sobre substituição processual. Por buscarem minimizar os prejuízos à atuação sindical, decorrentes da restrição legislativa à legitimidade ativa ad causam para os sindicatos em geral demandarem em juízo na defesa dos interesses de suas categorias, tais ações são representativas dos usos da judicialização para arbitragens de interesses em conflito, segundo a classificação de Taylor e Da Ros.

Os partidos políticos (PDT, PSDB, PCdoB e PT) da base oposicionista apresentaram cinco ADIs em matéria trabalhista (294, 298, 300, 357, 359), que impugnavam regras das Medidas Provisórias 190 (suspensão das decisões dos TRTs) e 211 (sobre salário).

\subsection{O ÁPICE DA JUDICIALIZAÇÃO: A FLEXIBILIZAÇÃO DO DIREITO DO TRABALHO (1998)}

O segundo momento significativo de judicialização trabalhista no Supremo Tribunal Federal ocorreu em 1998, por ocasião do ápice da política de reforma trabalhista neoliberal promovida naquela década.

Em 1998 foram ajuizadas 26 Ações Diretas, a demonstrar que a temática trabalhista volta a se destacar entre as ADIs propostas no STF. Entretanto, o perfil dos atores que ingressam com as ações é alterado. A ampla maioria das ações (19) foi proposta por entidades representativas dos trabalhadores e de partidos políticos que contestavam as reformas liberalizantes promovidas pelo governo Fernando Henrique Cardoso e a maioria parlamentar neoliberal formada por partidos de centro-direita. Oito ações foram propostas por partidos políticos do bloco de oposição à aliança governista capitaneada por PSDB, DEM, PTB e outros. A Lei 9.601 de 1998 foi objeto de contestação pelo PT, PDT e PCdoB (ADI 1764) e PSTU (ADI 1767). O reajuste do salário mínimo foi objeto de judicialização pelo PT, PDT e PCdoB (ADI 1830). O PT e o PDT também se sublevaram contra a Medida Provisória 1709, que estabeleceu o contrato de trabalho a tempo parcial (ADI 1871 e 1709). A judicialização foi utilizada como tática de oposição para se insurgir contra o desvirtuamento da ideia de Estado Social presente na Constituição de 1988.

Quanto à matéria trabalhista objeto dos atos impugnados, a sua ampla maioria diz respeito à duração do trabalho (Banco de Horas) e às novas 
formas de contratação mais flexíveis. Com efeito, naquele ano, o Poder Executivo adotou um "ativismo legislativo" (VIANNA et al., 2010), no sentido de flexibilizar tanto a entrada na relação empregatícia quanto a duração do trabalho. Foram ampliadas as hipóteses de contratação por tempo determinado e criado o sistema de compensação de horários por meio de banco de horas (Lei 9.601, de 1998), introduzidas regras para contratos em tempo parcial com a anualização da duração semanal de 44 horas para efeito de compensação (MP 1.709 de 1998), além de diversas alterações no instituto do repouso remunerado aos domingos (inúmeras reedições da MP 1.539, de 1997).

Do ponto de vista do tipo de dispositivo impugnado, em comparação com o período anterior (1990), no qual os atos do Poder Executivo monopolizaram as impugnações, em 1998 a contestação envolveu tanto os atos normativos oriundos do Executivo quanto as regras originárias do Poder Legislativo. Doze leis federais e um decreto legislativo foram atacados, bem como nove Medidas Provisórias e um decreto do Executivo. A pulverização das espécies normativas é resultado de um processo político no qual o Presidente da República, embora utilizando demasiadamente Medidas Provisórias, não monopolizou, ao menos em seu primeiro mandato, a atividade legislativa, que permaneceu intensa no Congresso Nacional.

\subsection{A JUDICIALIZAÇÃO ADQUIRE CULMINÂNCIA E COMPLEXIDADE}

O terceiro momento representativo de ajuizamento de Ações Diretas de Inconstitucionalidade ocorreu no ano de 2008, quando 19 ADIs foram propostas. Os dados examinados sugerem a existência de uma mudança no tipo de contestação realizada perante o Supremo Tribunal Federal e comprova tendência já verificada no ano anterior, pois demonstra o deslocamento no eixo da judicialização, seja do ponto de vista dos atores demandantes, seja sob o prisma do ente que edita o dispositivo legal questionado. A complexidade do sistema de fontes trabalhistas e a pluralidade dos interesses econômicos e sindicais emergem com força.

As mudanças no tipo de judicialização e a complexidade adquirida, no último período, podem ser constatadas no ano de 2008 em três aspectos.

Primeiro, do ponto de vista dos atores que postulam a declaração de inconstitucionalidade, verifica-se que as confederações patronais assumem o 
protagonismo na contestação das regras por intermédio das ADIs, sendo responsáveis por nove das 19 ajuizadas no período, enquanto as confederações sindicais dos trabalhadores e os partidos políticos aparecem equilibrados, com três ações cada.

Dentre os partidos políticos, somente um deles assume a defesa de sua concepção sobre o direito constitucional dos trabalhadores - o Partido Socialismo e Liberdade (PSOL) -, pois as duas outras ADIs foram movidas por partidos considerados alinhados com os interesses empresariais - PSDB e DEM - e questionam regras que diminuem o desequilíbrio de poder na sociedade em prol dos trabalhadores e de suas entidades representativas. O PSOL apresentou a ADI 4027, na qual impugna a Lei no 11.603, de 2007, que, ao regular o trabalho aos domingos no comércio, o estende para o comércio atacadista. Segundo o PSOL, não há qualquer conveniência pública na abertura do comércio atacadista aos domingos, assim como vislumbra redução dos direitos trabalhistas na autorização para o trabalho no comércio nos feriados. Na ADI 4015, o Governo do Pará impugna Portaria nº 219/06, do Tribunal Regional do Trabalho da $8^{\mathrm{a}}$ Região, que fixa critérios concernentes aos débitos de pequeno valor nos termos do artigo 100, $\S 3^{\circ}$ da CRFB, sob a alegação de usurpação da competência legislativa. Já o Democratas (DEM) questiona a Lei 11.648, de 2008, que reconheceu formalmente as centrais sindicais e lhes destinou parte dos recursos da contribuição sindical das categorias profissionais (ADI 4067). Aliás, o DEM assumirá o papel de protagonista na utilização da tática de oposição à atividade legislativa do último quinquênio analisado, pois em 2011 será o autor, junto com o Partido Popular Socialista (PPS) e o PSDB, da Ação 4568, que ataca a política de valorização do salário mínimo estabelecida pela Lei no 12.382 de 2011.

Primeiras protagonistas das ações diretas de inconstitucionalidade propostas contra as reformas trabalhistas neoliberais dos anos 1990, as Centrais Sindicais assumem, neste contexto, o papel de defensoras das regras contestadas pelo DEM e passam a atuar nessas ADIs. Na ADI 4067, por exemplo, a CUT, a União Geral dos Trabalhadores (UGT) e a Força Sindical foram admitidas como amicus curiae para a defesa da constitucionalidade dos artigos $1^{\circ}$, II, e $3^{\circ}$, da Lei 11.648 , de 2008, impugnados pelo partido Democratas.

De toda sorte, as ações diretas propostas por partidos políticos declinaram durante todo o período do Governo Luiz Inácio Lula da Silva. 
Como observamos anteriormente, tal decréscimo pode ser explicado por dois fatores que atuaram em conjunto:

$\mathrm{O}$ primeiro relaciona-se à circunstância de que os partidos que tradicionalmente ajuizavam as ADIs - PT, PCdoB, PDT e PSB, de forma isolada ou em litisconsórcio, passaram a formar a base do governo. $\mathrm{O}$ segundo fator advém da análise sobre a produção legislativa do primeiro mandato do presidente Luiz Inácio Lula da Silva, a qual permite a Vianna et al. concluírem que 'o impulso flexibilizador foi utilizado com parcimônia pelo presidente Lula, atacando a legislação trabalhista de forma lateral'. (SILVA; MOURA, 2014, tradução livre).

Dentre as entidades de classe nacional, a Associação Nacional de Magistrados do Trabalho (ANAMATRA) figura no rol de autores que contestaram a inconstitucionalidade de dispositivos normativos no ano de 2008. Na ADI ${ }^{\circ} 4168$, a entidade requer a inconstitucionalidade de parte das Resoluções Administrativas 1128, de 2006, e 1261, de 2007, do Tribunal Superior do Trabalho, que estabeleceram o Regimento Interno da Corregedoria-Geral da Justiça do Trabalho. Na ação, alega-se a existência de inconstitucionalidades formais e materiais, e visa-se a limitar o poder do Corregedor da Justiça do Trabalho, investido de poder jurisdicional anômalo que viola os princípios do devido processo legal, do juiz natural, do sistema recursal, da ampla defesa e do contraditório. Do ponto de vista do dispositivo impugnado, essa ADI é representativa do segundo aspecto relevante, que denota a complexidade adquirida pela política trabalhista no período.

Enquanto nos demais períodos de intensa judicialização as contestações à inconstitucionalidade atacavam fortemente Medidas Provisórias, no último período outras foram as regras, oriundas do Poder Executivo, que mereceram atenção dos atores sociais. No ano de 2008, a atuação do Ministério do Trabalho e Emprego na regulamentação do registro sindical foi objeto de cinco ações que impugnaram a Portaria 186, de 10 de abril de 2008. Além da atuação normativa dos poderes Executivo e Legislativo, as ações diretas propostas pelo PSDB e pela ANAMATRA indicam que a atuação regulamentar da Justiça do Trabalho também ganhou espaço dentre as ações em matéria trabalhista. As demandas se voltaram não somente para atacar regras editadas por outros poderes da União, como também para aduzir a inconstitucionalidade de normas que procederam dos Estados e dos Municípios. Em 2008, pela primeira vez desde a Constituição 
de 1988, parcela significativa das ADIs interpostas desafiaram normas provenientes dos Estados e Municípios. Este é o terceiro aspecto.

Em 2008, entre as seis leis estaduais impugnadas, quatro eram originárias do Estado do Rio de Janeiro, sendo que três delas criavam feriados estaduais e uma estabelecia obrigatoriedade de exame preventivo contra câncer de mama nas trabalhadoras. Também foram objeto de ADI uma lei de Rondônia, que proibia pesca profissional nos rios do Estado, e uma lei do Distrito Federal, que estabelecia um índice mínimo de 5\% para contratação pelas empresas de pessoas com mais de 45 anos de idade. Embora desde a reforma constitucional de 1926 a União detenha a competência para legislar sobre direito material e processual do trabalho, a centralidade do trabalho na vida do país, em suas múltiplas dimensões, ultrapassa a legislação trabalhista em sentido estrito, e a existência significativa de ADIs que impugnam regras estaduais e municipais indicam que, para além do Congresso Nacional, a atividade legislativa prossegue sendo intensa nos legislativos municipais e estaduais.

$\mathrm{Na}$ contestação a regras estaduais, não somente confederações representativas de categorias econômicas assumem o polo ativo. No ano de 2008, por exemplo, o Governo do Distrito Federal contestou a Lei Distrital $n^{\circ}$ 4.118, de abril de 2008, que obriga a contratação de pessoas com mais de 40 anos de idade, sob o fundamento de violação à regra de competência legislativa da União, como também de ofensa aos princípios da livre iniciativa e livre concorrência (ADI nº 4082).

Algumas recorrências persistem no período com o uso da judicialização tanto como tática de oposição, para arbitragem de interesses em conflito, quanto como instrumento de governo, ainda que por atores diferenciados. Os partidos de centro-direita demandam contra as regulamentações que são desfavoráveis ao empresariado e transferem recursos de poder às entidades sindicais de trabalhadores (tática de oposição); entidades representativas de magistrados postulam contra o que reduz o espaço de decisão dos magistrados e amplia os mecanismos de controle correicional (arbitragem de interesses em conflito); e os chefes do Poder Executivo estadual impetram contra a regulamentação de matéria trabalhista nos estados e/ou distrito federal (judicialização como instrumento de governo).

A culminância da judicialização em matéria trabalhista na primeira década do século é representativa da complexidade do mundo do trabalho, dos interesses em litígio e demonstra a riqueza que o estudo das demandas 
propostas perante o Supremo Tribunal Federal pode oferecer para uma compreensão mais ampla do mundo do trabalho.

\section{CODA}

É importante retomar as reflexões de Peter Häberle: uma "sociedade é livre e aberta na medida em que amplia o círculo dos intérpretes da Constituição" (1997, p. 40). A Constituição de 1988 é um marco na abertura da jurisdição constitucional aos atores políticos e à sociedade civil organizada. Sem sombra de dúvidas, a abertura procedimental promovida no processo constitucional ampliou a participação da sociedade civil no processo constitucional. No entanto, há que se observar que o acesso à justiça também é desigual no âmbito constitucional, pois, além de obstáculos econômicos e sociais, os empecilhos processuais existem e demonstram como as desigualdades na sociedade livre representam aberturas diferenciadas para exercer a atividade argumentativa e defender suas ideias de direito no âmbito da Constituição, ao menos no que se refere aos atores sociais.

No cenário da jurisdição constitucional, afirmam Marrafon e Kozikoski, "há que se conferir especial proteção em prol da participação dos grupos vulneráveis, minorias, categorias de pessoas e entidades representativas da sociedade civil" (2012, p. 54), motivo pelo qual o contraditório fluido pode representar importante instrumento de legitimação das decisões, mormente para se evitar um desequilíbrio informacional decorrente de uma atuação desigual e polarizada no processo (KOZIKOSKI, 2013).

A Constituição de 1988 deslocou topograficamente a regulação do trabalho do capítulo da ordem econômica para o título dos direitos fundamentais, substituindo o enfoque mercantil e de intervenção do Estado no domínio econômico até então predominante, atribuindo relevância aos direitos sociais, dentre os quais os do trabalho, compreendidos como direitos fundamentais. Contudo, a realização de um ideário constitucional de valorização do trabalho e de progressividade dos direitos sociais e de proteção aos trabalhadores prossegue sendo disputada no cenário público brasileiro. Em todas as instâncias e arenas de regulação - do local de trabalho ao Congresso Nacional - a legislação do trabalho é disputada e os atores políticos e sindicais demandam pela afirmação de suas ideias de direito e dos limites e possibilidades de concretização das normas constitucionais. 
O panorama das ações diretas de inconstitucionalidade propostas perante o Supremo Tribunal Federal que envolve regras atinentes ao mundo laboral permite, do ponto de vista dos demandantes, (a) observar a pluralidade dos intérpretes da Constituição do Trabalho; (b) refletir sobre os usos da judicialização pelos atores políticos, governamentais e sindicais e (c) apontar os momentos cruciais do pós-constituinte, nos quais o trabalho adquiriu relevância na litigância perante o Supremo Tribunal Federal e, com isso, observar os contextos da judicialização.

Embora não seja possível traçar uma correspondência necessária entre os momentos de intensa judicialização e de amplo debate público sobre o direito do trabalho, é razoável notar que os anos de maior judicialização demonstram contextos políticos distintos. A disputa pelo valor econômico do trabalho, pelo conteúdo material dos direitos e pelos recursos de poder e capacidade de ação no mundo sindical, apesar de contínuas, marcaram, com forças distintas, os três períodos em que a judicialização da temática trabalhista foi relevante na pauta do Supremo Tribunal Federal.

De toda forma, o estudo das demandas permite olhar não somente para os atores que contestam as regras e defendem suas leituras da Constituição, mas também para os dispositivos impugnados, que demonstram que os conflitos trabalhistas passaram a ser disputados em múltiplas instâncias de regulação. Além do Congresso Nacional e da Presidência da República, o STF também se mostra como espaço oportuno por meio das ações diretas. O mundo do trabalho, afinal, fragmenta-se e se torna cada vez mais complexo e dinâmico.

Por fim, não custa relembrar que o deslocamento do olhar dos acórdãos e das decisões proferidas para as petições e alegações trazidas na propositura das ações diretas é consentâneo com uma compreensão metodológica que recusa a tradicional abordagem, segundo a qual a interpretação constitucional é tarefa exclusivamente de técnicos, exegetas, cabendo à Corte suprema dar a última palavra sobre o que é ou vem a ser a Constituição.

Deste modo, em sendo a abertura da jurisdição constitucional uma construção da democracia, a proeminência do Supremo Tribunal Federal em matéria trabalhista e a participação de outros atores, que não os representativos de empregados e empregadores na definição das normas de direito do trabalho, são fenômenos novos que mostram a riqueza dos estudos das configurações institucionais, privilegiam a dialética entre instituinte/instituído e a possibilidade viva de captar as leituras que os atores fazem da Constituição pelas teses defendidas perante o Poder Judiciário. 


\section{REFERÊNCIAS}

BERG; J. KUCERA, D. Labour Institutions in the developing world: historical and theoretical perspectives. In: In Defence of Labour Market Institutions: Cultivating Justice in the Developing World. New York: Palgrave Macmillan, ILO, 2008, p 9-31.

HÄBERLE, P. Hermenêutica constitucional. A sociedade aberta dos intérpretes da Constituição: Contribuição para a interpretação pluralista e procedimental da constituição. Porto Alegre: Sérgio Antônio Fabris Editor, 1997.

MARRFON, M. A.; KOZIKOSKI, S. Legitimidade da jurisdição constitucional e a possibilidade de atuação de Senador da República como amicus curiae no contexto da nova racionalidade processual. In: Revista Brasileira de Estudos Constitucionais. Belo Horizonte: Fórum, out.dez. 2012, p.115-1137.

MOURA, E. K. V. Trabalho e Constituição: Ações diretas de inconstitucionalidade e os desafios da regulação do tempo de trabalho no Brasil. 2013. Dissertação (Mestrado em Teorias Jurídicas Contemporâneas), Programa de Pós- Graduação em Direito, Rio de Janeiro: Universidade Federal do Rio de Janeiro, 2013.

KOZIKOSKI, S. Garantismo, contraditório fluido, recursos repetitivos e incidentes de coletivização. RODRIGUES, W. S. , SOUZA, M. C. X. (Orgs.) O novo Código de Processo Civil: o novo CPC e o desafio das garantias fundamentais. Rio de Janeiro: Elsevier, 2013.

SILVA, S. G. C. L. Decisões judiciais e (des)construção dos direitos: uma revisita à interpretação dos direitos coletivos pelos tribunais superiores. In: COUTINHO, F.C. et al. O Mundo do Trabalho. Leituras críticas da jurisprudência do TST: em defesa do direito do trabalho. São Paulo: LTr, 2009, p. 418-438.

. Relações Coletivas de Trabalho: configurações institucionais no Brasil contemporâneo. São Paulo: LTr, 2008. 
. Direitos fundamentais, Garantismo e Direito do Trabalho. In: Revista da OAB/RJ. Rio de Janeiro, OAB/RJ, v. 27, 2012.

. Reforma do Judiciário e Justiça do Trabalho: Esboço para a avaliação do legado reformador no âmbito do direito de greve. In: COUTINHO, G. F.; FAVA, M. N. (Org.). O que estão fazendo da Nova Competência da Justiça do Trabalho? Análise crítica da jurisprudência do STF, do TST e do STJ após a EC 45/2004. São Paulo: LTr, 2011, p. 611-639.

. et al. Ações Diretas de Constitucionalidade, Inconstitucionalidade e Arguições de Preceito Fundamental propostas perante o Supremo Tribunal Federal de 1988 a 2013 em matéria trabalhista: Banco de Dados. Rio de Janeiro, Grupo de Pesquisa Configurações Institucionais e Relações de Trabalho. CIRT- PPGD-UFRJ, abril de 2013.

. IGREJA, C. de O; MOURA, E. K. V. Constituição e Trabalho: um exame sobre as Ações Diretas de Inconstitucionalidade propostas perante o Supremo Tribunal Federal que versam sobre direitos do trabalho. XXXI Jornada Giulio Massarani de iniciação científica, artística e cultural. Rio de Janeiro: Universidade Federal do Rio de Janeiro, CCJE, 2009.

. MOURA, E. K. V. Constitutionality Control about working matters in Brazil between 1988 and 2012. Anais do 26th World Congress of Philosophy of Law and Social Philosophy of the International Association for Philosophy of Law and Social Philosophy. Belo Horizonte, 2014 (no prelo).

SOUZA NETO, C. P. de. SARMENTO, D. Direito constitucional: teoria, história e métodos de trabalho. Belo Horizonte: Fórum, 2012.

TAYLOR, M. M.; DA ROS, L. Os partidos dentro e fora do poder: a Judicialização como resultado contingente da estratégia política. In: Revista Dados. Rio de Janeiro v.51, n.4, 2008. Disponível em: <http:// www.scielo.br/pdf/dados/v51n4/02.pdf>. 
VIANNA, L.W. et al. A constitucionalização da legislação do trabalho no Brasil: uma análise da produção normativa entre 1988 e 2008. Centro de Estudos Direito e Sociedade (Cedes). Brasília: Fundação Astrogildo Pereira (FAP), 2010.

Artigo recebido em: 01/08/2014 Aprovado para publicação em: 20/08/2014

Como citar: SILVA, Sayonara Grillo Coutinho Leonardo. MOURA, Eleonora Kira Valdez. O que os atores demandam perante o Supremo Tribunal Federal em matéria trabalhista? Revista do Direito Público. Londrina, v.9, n.2, p.115-133, mai./ago. 2014. DOI: 10.5433/1980-511X.2014v9n2p115. 